\title{
PRÁTICA ARTÍSTICA NO EAD: STREAMING
}

\author{
SANTOS/SP JULHO/2018
}

\author{
Rubens de Souza - UNIMES - rubens.souza@unimes.br \\ Tipo: Relato de Experiência Inovadora (EI) \\ Categoria: Métodos e Tecnologias \\ Setor Educacional: EDUCAÇÃO SUPERIOR
}

\begin{abstract}
RESUMO
O modelo pedagógico estabelecido aos ambientes virtuais de aprendizagem, basicamente vinculam o depositório de conteúdos, alguns ferramentas de interação, a mais frequente é o fórum de discussão $e$ as avaliações. A licenciatura de Artes Visuais, a partir de um evento denominado Jornada Interdisciplinar, que vinculou os cursos de Música e Letras busca novos entrelaçamentos, a partir do uso de streaming, ou web conferência, ou vídeo conferência em suas ações e sequências didáticas, como forma de ampliar a interação entre os estudantes, viabilizar as atividades práticas e melhor 0 processo de ensino e aprendizagem.
\end{abstract}

Palavras-chave: Streaming. Ensino. Atividade prática. 


\section{Prática artística no EaD: Streaming}

Relato de Experiência Inovadora (EI)

Educação Superior - Métodos e Tecnologias

\section{Resumo:}

O modelo pedagógico estabelecido aos ambientes virtuais de aprendizagem, basicamente vinculam um depositório de conteúdos, algumas ferramentas de interação sendo a mais frequente o fórum de discussão e as avaliações. A licenciatura de Artes Visuais, a partir do evento denominado Jornada Interdisciplinar, com os cursos de Música e Letras proporcionou entrelaçamentos, com o uso de streaming, ou web conferência, ou vídeo conferência em suas ações pedagógicas e sequências didáticas, como forma de ampliar a interação entre os estudantes, viabilizar as atividades práticas e melhorar o processo de ensino e aprendizagem.

Palavras-chave: Streaming. Ensino. Atividade prática.

\section{Introdução}

Frequentemente os cursos de EAD solicitam aos alunos atividade dissertativa, em que o tutor avalia. Há um fórum para as interações e análises das proposições. A expectativa do professor e do tutor é que essa interação resulte em quantidade de postagens, como forma de aferir a participação do aluno. Há um prazo para tais ações e esse costume se repete para diferentes componentes curriculares.

O curso de Artes Visuais da UNIMES Virtual percorre essa metodologia, vale destacar, que não se trata de uma ação pedagógica superada ou descartada, no entanto, novos procedimentos podem ser adicionados ao processo de ensino e aprendizagem.

No mês de maio do corrente ano, o curso de Artes Visuais elaborou um evento, aos alunos da modalidade a distância, pelo sistema streaming. Nessa vivência de sucesso, estabelece-se a hipótese de que esse recurso streaming torna-se plausível para a sequência didática elaborada pelo curso de Artes Visuais da UNIMES Virtual. 
Justifica-se esta proposição ao aferirmos as vantagens, que sobrepõem às dificuldades ao adotar tal metodologia, rompendo assim, procedimentos repetitivos no Ambiente Virtual de Aprendizagem - AVA que desmotivam os estudantes.

Esse relato de experiência tem como objeto expor as vantagens do recurso streaming para as interações: professor - aluno, aluno - aluno. Ainda, enfatizar as vantagens para a apreensão de atividades avaliativas, principalmente as de caráter prático.

Sendo assim fundamentaremos esse artigo, a partir do livro: Métodos de exposição de conteúdos e de avaliação em EaD de Silvia Hidal, por fundamentar a importância da mediação. Ainda João Mattar, em seu artigo: Aprendizagem em ambientes virtuais além de outros autores que estruturam as instâncias do processo de ensino e da aprendizagem.

Somam-se aos procedimentos metodológicos os resultados de uma pesquisa aplicada aos alunos participantes do evento denominado: Jornada Interdisciplinar.

A Jornada Interdisciplinar promovida e elaborada pela UNIMES Virtual foi um evento que relacionou as Licenciaturas: Artes Visuais, Letras e Música. O propósito de oferecer vivências e práticas pedagógicas aos 3.118 estudantes regularmente matriculados, dos referidos cursos que participaram no evento. Esse projeto interdisciplinar amparou-se na Abordagem Triangular da pesquisadora $\mathrm{Dr}^{\mathrm{a}}$ Ana Mae Barbosa em suas fundamentações metodológicas de ensino de arte e arte comparada para a educação básica. Nessa perspectiva, todas as atividades planejadas foram pensadas para sua aplicabilidade para a escola regular.

A Jornada estabeleceu três atividades por noite. Preferiu-se o horário noturno, pois é o período de maior acesso dos estudantes.

O sistema streaming, que é o site do YouTube, além de amigável com o sistema Moodle é ideal para transmissões de vídeo em tempo real.

Percebe-se que a arquitetura pedagógica adotada no ambiente virtual da UNIMES, que utiliza a plataforma Moodle é fortemente alicerçada em conteúdos teóricos e prevê uma perspectiva interacionista. Ainda, o método predominante para exposição de conteúdo se estabelece predominantemente por meio da escrita, apesar das vídeoaulas. Ao revisitarmos as teorias de Vygostky identificamos que o indivíduo ao aprender, em seu processo intelectual "intrapessoal", considera os fatores sociais "interpessoal". Essa teoria é conhecida como sociointeracionista, sociohistórica ou sociocultural. Ou seja, 
resultamos também das interações, dos fatores históricos e das manifestações culturais. Essa dinâmica dialética estrutura aspectos psicológicos do indivíduo (atenção, memória, capacidade de abstrair e solucionar problemas, entre outros).

Vários autores pesquisam sobre a interação em ambientes virtuais de aprendizagem, mas, também pesquisam sobre aspectos afetivos e acolhimento. Evidentemente, alguns elementos são importantes e necessários para aos alunos. As teorias psicológicas, (behavionistas[1], jamesiana[2], darwinista[3], cognitivista[4] e socioconstrutivistas[5]) são fundamentais para entendermos o ciclo de evasão, processo de ensino e aprendizagem, adaptabilidade a sistemas mais ou menos complexos restritos em ambientes virtuais de aprendizagem, convívio, etc.

Silva Hidal cita, em seu livro, (SCHINITIMAN, 2010, p. 5 -7) que aborda estilos de aprendizagem:

Ativo, Reflexivo, Racional, Intuitivo, Visual, Verbal, Sequencial e Global.

Ativo: aprende na prática, gosta prefere trabalhar só; Racional: concreto, prático, busca os fatos e os procedimentos; Intuitivo: conceitual, busca os significados e as teorias e é inovador; Visual: prefere a representação visual da aula, (diagramas, fotografias, fluxogramas); Verbal: prefere explicações escritas e faladas; Sequencial: aprende pela execução; Global: pensamento sistêmico, holístico de pequenas etapas, linear e ordenado, aprende por insights.

Mattar menciona: John Dewey define uma corrente que aborda a educação de crianças, mas suas palavras poderiam ser tomadas como o design instrucional falando sobre educação a distância, ou seja, essa continua sendo uma teoria que fundamenta a prática do ensino e da aprendizagem hoje, mesmo no caso do uso de ambientes virtuais.

Destaca-se Paulo Freire, ao mencionar o modelo educacional, (presencial), em que o professor repete a prática de "depósito de informações", aos alunos que são vistos como "recipientes vazios". O estudante deve memorizar e repetir as verdades do professor. Portanto, "Educação bancária". 
Em lugar de comunicar-se, o educador faz "comunicados" e depósitos que os educandos, meras incidências, recebem pacificamente, memorizam e repetem. Eis aí a concepção "bancária" da educação, em que a única margem de ação que se oferece aos educandos é a de receberem os depósitos, guardá-los e arquivá-los [...]. No fundo, porém, os grandes arquivados são os homens [...]. Arquivados, porque, fora da busca, fora da práxis, os homens não podem ser. Educador e educando se arquivam na medida em que, nesta distorcida visão da educação, não há criatividade, não há transformação, não há saber [...]. (FREIRE, 2013, p.80)

No ambiente virtual essa prática, defini-se como modelo pedagógico, estabelecido por alguns autores, pode causar determinada monotonia ao curso e/ou componente curricular.

Será importante destacar as teorias de Freire:

Outro saber necessário à prática educativa, e que se funde na mesma raiz que acabo de discutir - a da inconclusão do ser que se sabe inconcluso -, é o que fala do respeito decido à autonomia do ser educando. Do educando criança, jovem ou adulto. Como educador, devo estar constantemente advertido com relação a este respeito que implica igualmente o que devo ter por mim mesmo (FREIRE, 1996, p. 65-66).

\section{Procedimento Metodológico}

A partir da teoria de Dra Ana Mae Barbosa, estabeleceu-se para o evento práticas, para o aluno elaborar algum tipo de ação e enviar ao ambiente virtual de aprendizagem, ou seja: "fazer".

O evento explorou os sentidos e as percepções dos alunos para as imagens, para o texto e para a música. Assim, as manifestações artísticas; imagem e texto, verbais/visuais estiveram presentes nas propostas elaboradas e apresentadas ao vivo para os alunos.

As teorias e as pesquisas de Barbosa são fundamentadas em Dewey[6] e no Movimento da Escola Nova[7], em Pernambuco, que culminaram na metodologia denominada Abordagem Triangular. 
Trata-se de procedimentos estabelecidos por ação ou sequência didática, onde o docente fará a contextualização da obra de arte, sua leitura e por fim o fazer artístico.

Essa proposta engloba vários aspectos da aprendizagem, como: leitura de imagem; elementos da arte: conhecer e reconhecer objetos artísticos; história da arte; biografia de artistas; fazer artístico: vivências artísticas com diferentes técnicas e modalidades artísticas.

Ou seja, a Jornada Interdisciplinar, proporcionou em sua programação a produção, a fruição e a reflexão da arte.

\section{Apresentação e discussão dos resultados}

Ao confrontarmos algumas teorias apresentadas com as experiências obtidas no evento: Jornada Interdisciplinar fica muito evidente a participação e aproveitamento do aluno se ampliam, a partir do streaming.

O primeiro dia do evento: 21/03/2018 contou com 781 participantes. Vale destacar 0 sistema streaming grava os vídeos transmitidos ao vivo.

Após sua transmissão o acesso às atividades do primeiro dia totalizou 1554 participações. Para esse evento o YouTube registra: 2.089 visualizações acessível em: https://www.youtube.com/watch?v=2SrdwrDIBtl. O dia 22/03/2018 registrou 1.100 visualizações e em nosso ambiente virtual: 1893 acessos e no último dia, o ambiente virtual somou 1260 acessos. No YouTube 634 visualizações[8].

O streaming é vastamente explorado em redes sociais, pois é capaz de comprimir vídeos, e isso viabiliza sessões ao vivo, via Internet, em velocidade surpreendente, sem a necessidade de armazenar os dados em um computador.

O uso de recursos em áudio e vídeo no ambiente virtual é imprescindível, e exige que o estudante tenha software instalado em seu computador ou sistema mobiles para receber esses conteúdos. Vale destacar, o uso e a conexão à Internet devem ser suficientes para receber e transmitir vídeos em tempo real. 
A aula via streaming solicita que o professor tenha razoável familiaridade com câmera, conhecimento dos recursos, que podem ser disponíveis para dispositivos móveis e computadores.

O recurso é extremamente útil, para que o estudante envie suas dúvidas e para esclarecimentos de atividades práticas.

\section{Considerações finais}

O ambiente virtual de aprendizagem, ao contrário do que algumas instituições impõem, como padronizações e repositório de conteúdos abrem novos desafios e grandes possibilidades. O sistema streaming por si oferece novas análises metodológicas, pois, requer baixo investimento e apresenta muitas vantagens aos estudantes, como: proximidade com o professor e/ou tutor, agilidade para esclarecimentos de dúvidas, facilidade para explicações de atividades práticas, entre outros aspectos.

No entanto, é necessário que o professor e/ou tutor tenha domínio e facilidade para dinamizar a videoconferência, equipe técnica que auxilie no momento da transmissão, agendamento prévio, para que os alunos participem da atividade ao vivo. E confirmação se o aluno possui condições em seu sistema pessoal

Para esse tipo de aula, ou evento online, sua abrangência é garantida respeitando assim, as condições do estudante que escolhe o ensino a distância.

A transmissão ao vivo aceita a inclusão de outros recursos da informática, com softwares de imagens, gráficos, vídeos, áudios, textos, etc. Ou mesmo demonstrações de experimentos e ações predominantemente de caráter prático.

\section{Referências}

HIDAL, Silvia Luisa Servos Tabacow. Métodos de exposição de conteúdos e de avaliação em curso EaD. São Paulo: Labrador, 2017. 
MATTAR, João. Aprendizagem em ambientes virtuais: teorias, conectivismo e MOOCs. Disponível:

http://www.pucsp.br/pos/tidd/teccogs/artigos/2013/edicao_7/2-aprendizagem_em_ambie ntes_virtuais-joao_mattar.pdf. Acesso, 12 mai 2018.

VYGOSTKY, L. S. A formação social da mente. São Paulo: Martins Fontes, 1989.

FREIRE, P. Pedagogia da autonomia: saberes necessários à prática educativa. 25를 Ed. São Paulo: Paz e Terra. 1996.

BARBOSA, Ana Mae Tavares Bastos. Arte - Educação: Leitura no subsolo. $7^{\text {a }}$ Ed. São Paulo: Cortez, 2008.

Ana Mae Tavares Bastos. Tópicos utópicos. Belo Horizonte: C/ Arte, 1998.

BRIGHENTE, M. F.; MESQUIDA, P. Paulo Freire: da denúncia da educação bancária ao anúncio de uma pedagogia libertadora. Pro-Posições, v. 27, n. 1, p. 155-177, jan-abr, 2016.

DEWEY, John. Arte como Experiência. São Paulo: Martins Fontes, 2010.

DEWEY, John. Experiência e Educação. 15ª Ed. São Paulo: Cia. Editora Nacional, 1979.

FREIRE, P. Pedagogia do Oprimido. 54 ed. Rio de Janeiro: Paz e Terra, 2013.

[1] Correntes de pensamento amparadas nos fundamentos de Sknner e Watson e 
pressupões que uma experiência emocional pode vincular fatos e eventos do meio ambiente.

[2] Surgiu nas teorias de William James, ao analisar mudanças fisiológicas e corporais.

[3] A teoria da evolução como seleção natural, proposta por Darwin.

[4] A perspectiva cognitivista sustenta que o indivíduo expressa diferentes emoções, como respostas ao meio.

[5] As emoções são resultados da cultura e das regras de determinados grupo social.

[6] John Dewey (1859 - 1952). Filósofo norte-americano, nascido em Burlington, E.U.A. reformolou o pensamento pedagógico no ensino, a partir da ação e da democracia e liberdade de pensamento como instrumentos para a maturação emocional e intelectual das crianças.

[7] A Escola Nova foi um movimento, ou corrente pedagógica, de renovação da educação com grande influência no século XX. Partindo da ideia de fundamentar o ato pedagógico na ação e atividade da criança (auto formação e atividade espontânea), transformou esta no centro de um aprendizado ativo, com significativa participação das teorias desenvolvidas pela sociologia da educação e psicologia educacional.

[8] Disponível: https://www.youtube.com/watch?v=WrXxrwyMWgM Acesso: 20 mai 2018. 